\title{
Prevalence and risk factors of swine tuberculosis in central Ethiopia
}

Kassa Demissie ${ }^{* 1}$, Jirata Shiferaw ${ }^{2}$, Girmay Medhin ${ }^{3}$, Aboma Zewude ${ }^{4}$, Asegedech Sirak ${ }^{5}$, Takele Abayneh ${ }^{6}$, Gezahegne $\mathrm{Mamo}^{7}$, Gobena Ameni ${ }^{3}$

${ }^{1}$ Department of Animal Sciences, College of Agriculture and Natural Resource Sciences, Debre Berhan University, Debre Berhan, Ethiopia, P.O. Box 445

${ }^{2}$ College of Veterinary Medicine and Agriculture, P.O. Box 34, Addis Ababa University, Bishoftu, Ethiopia

${ }^{3}$ Aklilu Lemma Institute of Pathobiology, Addis Ababa University, P.O. Box 1176, Addis Ababa, Ethiopia

${ }^{4}$ Ethiopian Public Health Institute (EPHI), P.O. Box 1242, Addis Ababa, Ethiopia

${ }^{5}$ National Animal Health Diagnostic and Investigation Center (NAHDIC), P. O. Box 04, Sebeta, Ethiopia

${ }^{6}$ National Veterinary Institute, P.O. Box 19, Bishoftu, Ethiopia

${ }^{7}$ College of Veterinary Medicine and Agriculture, Addis Ababa University, P.O.Box 34, Bishoftu, Ethiopia

*Corresponding author: Email: kassa.demissie@yahoo.com; Tel.: +251-911-993242, (K. Demissie)

\begin{abstract}
There is paucity of information in the epidemiology and pathology of tuberculosis in swine though the endemic occurrence of bovine tuberculosis was elucidated in Ethiopia. A cross-sectional study was employed to investigate the epidemiology of Mycobacterium tuberculosis complex and Mycobacterium avium complex in swine. The study was conducted from September 2016 to December 2017 using single intradermal comparative tuberculin test, gross pathology and histopathology. Tuberculin test was carried out in farmed swine of central Ethiopia while the necropsy at Addis Ababa Abattoirs Enterprise, Ethiopia. Of the total 329 heads of swine tuberculin tested by bovine purified protein derivative antigen, an animal level prevalence of 3\% (95\% CI: 2-6) and a herd level prevalence of $11 \%$ (95\% CI: 1-49) were observed at a cut-off value of $>2 \mathrm{~mm}$. Multivariable logistic regression analysis revealed the protective exposure effect of body condition to tuberculin test positivity in swine (Adjusted OR: 0.06 ; 95\% CI: $0.0-1.1 ; P: 0.055)$. Swine were predominantly in close proximity with dairy cattle which is an important risk factor for the transmission of bovine tuberculosis from cattle to swine. Necropsy study of tuberculosis-like le-
\end{abstract}


sions in 640 heads of swine revealed an overall lesion prevalence of 4.1\% (95\% CI: 2.8-6.0). In conclusion, the present study demonstrated the occurrence of swine tuberculosis in low prevalence in farmed swine and swine slaughtered at Addis Ababa Abattoirs Enterprise in central Ethiopia. Further in-depth study covering larger sample size and wider areas is warranted so as to identify the prevalent species and their zoonotic importance.

Keywords: Abattoir; Epidemiology; Ethiopia; Pathology; Swine; Tuberculosis

\section{Introduction}

Tuberculosis (TB) in animals is one of the most widespread infectious diseases in the world that can be described as a chronic granulomatous lethal disease caused by tubercle bacilli. It is widely distributed in developing countries where surveillance and control activities are often inadequate or unavailable. Risk factors for Mycobacterium bovis (M. bovis) in both animals and humans are present in the tropics (Cosivi et al., 1998). M. bovis infection has been reported in a wide range of animal species and is endemic in Africa (Cosivi et $a l .$, 1995). The course of TB is slow taking months or years to kill an infected animal and an animal can spread the disease to many other herd mates before it begins to manifest clinical signs (Elias et al., 2008; OIE, 2019).

The endemic nature of bovine TB (bTB) has long been reported in Ethiopia (Ameni et al., 2003; Shitaye et al., 2006; Sibhat et al., 2017). Swine are susceptible to Mycobacterium tuberculosis complex: MTBC (M. tuberculosis, M. bovis) and M. avium complex (MAC). Most of the TB compatible lesions in swine are localized along the digestive tract indicating the mode of infection is predominantly through ingestion of untreated milk from TB infected dairy cattle which suggests transmission between species (Barandiaran et al., 2011).

The MTBC can cause similar lesions with that of MAC (Agdestein et al., 2011). Based on molecular biological studies, swine were found to be a potential source of MAC infection for humans. Based on IS1245 restriction fragment length polymorphism (RFLP) analysis, at least $75 \%$ similarity of IS1245 RFLP types was detected among $61 \%$ human and 59\% swine isolates (Matlova et al., 2004). Serovars of MAC recovered from swine lymph nodes have been isolated from many environmental sources including soil, dust, water, feed, pig-compost and bedding (Gardener and Hird, 1989).

Skin test by purified protein derivative (PPD) antigen is a good tool and feasible to detect TB infected herds. Abattoir surveillance of animal TB is also a rou- 
tine procedure and cost-effective method of diagnosis (Radostits et al., 2007). The single intradermal comparative tuberculin test (SICTT) with bovine and avian PPDs is used mainly to differentiate between animals infected with $M$. bovis and those sensitized to tuberculin due to exposure to other mycobacteria or related genera. Due to their higher specificity and easier standardization, PPD products have replaced heat-concentrated synthetic medium tuberculins (OIE, 2009).

Retrospective pork inspection data analysis for the years 1996-2005 (Shitaye et al., 2006) at Addis Ababa Abattoirs Enterprise (AAAE) and necropsy study (Arega et al., 2013) at both AAAE and ALEMA Farms PLC (Bishoftu) were the only studies undertaken in swine in Ethiopia. Despite evidence that swine are affected by TB in Ethiopia, information on its epidemiology and pathology are still lacking. The current study of swine TB by skin test is the first of its kind executed in Ethiopia. Both skin test and necropsy studies generated useful information to all interested scientific audience with regard to swine TB. Therefore, the present study was initiated with the objectives of investigating the epidemiology of swine TB in dynamic herds of farmed swine in selected sites in central Ethiopia and its pathology in slaughtered swine at AAAE.

\section{Materials and methods}

\section{Study areas}

The study was conducted in farmed swine of Alage Agricultural, Technical and Vocational Education and Training (ATVET) College and farms in Bishoftu town and Addis Ababa from September 2016 to December 2017. Necropsy study was conducted in those swine brought to AAAE to be slaughtered for pork. Moreover, necropsy study was also carried out in those swine that reacted to both avian and bovine PPDs during SICTT. The study sites were located in central Ethiopia (Figure 1). The husbandry practices of swine in these study farms were intensive and semi-intensive. 


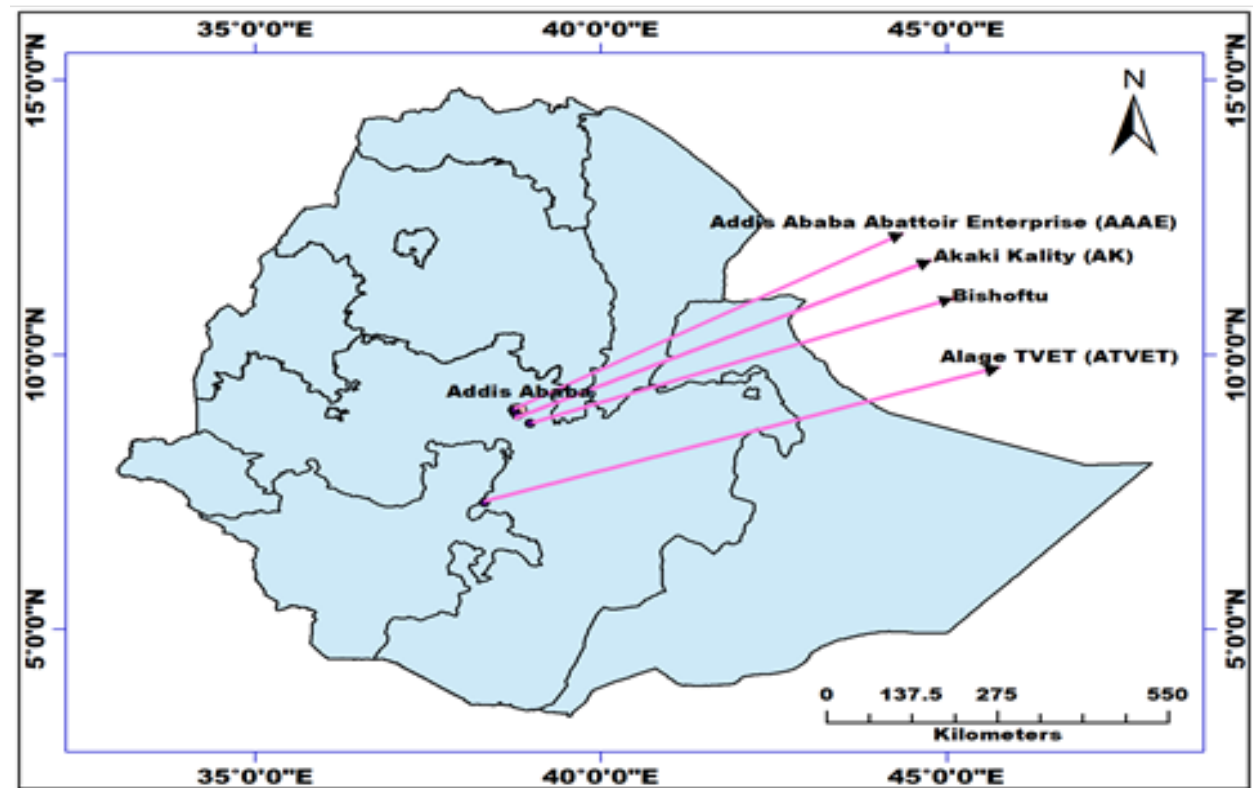

Figure 1. Map of the Study Areas

\section{Study animals and sampling}

Swine for skin testing were 329 heads included in 9 clusters. There were 12 clusters in the study areas representing 464 heads of swine. Necropsy examination of TB-like lesions was conducted in 640 heads of apparently healthy swine slaughtered at AAAE. Dairy cattle which were 28 in number (26 females and 2 males) herded with swine in one farm were also skin tested. A swine farm has equivalent meaning to a cluster or a herd. An individual cluster was taken as a unit of sampling. The sampling frame containing lists of clusters was established for each study site by the help of local livestock development agents. Clusters were selected by simple random sampling. Before the test, each swine was identified by ear tag or a temporary ID number using an indelible ink to write (for those without ear tags) on the back that could not be erased at least for a week. The ID numbers and all the corresponding data were recorded in a LogBook. 
Age, sex, body condition score (BCS), physiological state (open or pregnant), lactation status (non-lactating or lactating) and parity of swine were collected from farm records/owners and registered before skin test. The ages of swine were categorized into $<2$ years as young and $\geq 2$ years as adult based on the dentition formula adopted by USDA (2018). BCS of swine was categorized into poor, medium or good according to the guidelines given in CFSPH (2011). Sows that were more than 6 weeks of prepartum and postpartum (due to immunological hyporeactivity occurred in association with farrowing) and piglets with the age of above 3 months (piglets drinking colostrum from infected sows give positive reactions for up to 3 weeks after birth even though they may not be infected) were included in the skin test (Radostits et al., 2007). All apparently healthy swine brought for slaughtering to AAAE during the study period were included in necropsy study. Age, sex, origin and body condition scores of swine were recorded.

\section{Study design and sample size}

A cross-sectional study design was employed. The sample size for swine skin testing was determined using the formula for one-stage cluster sampling (Thrusfield, 2007) by considering:

$\mathrm{g}=$ number of clusters to be sampled; $1.96=$ multiplier of the $95 \%$ confidence interval (CI); $\mathrm{n}=$ the average number of swine per cluster (25); Pexp= expected prevalence $=0.5$ (since this study is the first of its kind in Ethiopia); $d=$ desired absolute precision (5\%) and $\mathrm{Vc}=$ assumed between-cluster variance $=0.02$ (previous experience in bovine TB studies of central Ethiopia). Accordingly, the calculated number of clusters to be sampled was nearly 46 representing 1150 heads of swine. However, the actual number of clusters representing the study population was 12 and the number of swine in the current study sites were small $(\mathrm{N}=464)$. Hence, the sample size needed an adjustment (Adj) as follows:

$\operatorname{Adjn}=\mathrm{G} \times \mathrm{g} / \mathrm{G}+\mathrm{g}=12 \times 9 / 12+9=6$ clusters

The required number of swine to be PPD tested was not restricted to 6 clusters. Therefore, 9 out of 12 clusters representing 329 heads of swine that fulfilled the inclusion criteria were tuberculin skin tested. Those swine $(n=135)$ that were under 3 months of age, late pregnant and near to farrow were not PPD tested. Five strong PPD reactors' swine (at $>2 \mathrm{~mm}$ cut-off point) which 
were herded with dairy cattle (4 heads) and alone ( 1 head) in Bishoftu were purchased, slaughtered and inspected in detail at necropsy facility of the College of Veterinary Medicine and Agriculture of Addis Ababa University (CVMA-AAU), Bishoftu, Ethiopia. Those 635 heads of swine which were presented for slaughter at AAAE were eligible for both detailed antemortem examination and necropsy. In total, 640 heads of swine were used for the current necropsy study. Antemortem examination and necropsy were conducted from July 2015 to March 2016 for the duration of seven months following the procedure described in FAO (1994).

\section{Skin testing}

Tuberculin testing of swine was carried out by SICTT following the protocols (Songer et al., 1980; OIE, 2009). Before injection of any PPD, the hair immediately caudal to the right and left base of the ears was shaved at one site on both sides of the neck (approximately $4 \mathrm{~cm}$ square) and the skin thickness of each shaved site was measured with $0.01 \mathrm{~mm}$ graduated callipers. All swine in 9 selected clusters were PPD tested. The right side was injected with bovine PPD $(0.1 \mathrm{ml}$ of $3000 \mathrm{IU} / \mathrm{ml})$ while the left side was injected with avian PPD $(0.1 \mathrm{ml}$ of $2500 \mathrm{IU} / \mathrm{ml}$ ) intradermally (PRiONiCS, Lelystad, The Netherlands) with $1 \mathrm{~mL}$ sterile insulin syringe with needle separately into the respective shaved sites.

The intradermally injected tuberculin into the raised fold was indurated so that a pea-like nodule was palpable. The tuberculin skin test result was read and the thickness of the skin at each injection site was measured again after 48 hours of post PPD injection (Songer et al., 1980; APHA, 2019). The test results were interpreted based on the guidelines provided by CFIA (2019) as follows: An increase in skin-fold thickness of more than $2 \mathrm{~mm}(>2 \mathrm{~mm})$ and/or oedema observed after the injection of avian or bovine tuberculin was considered positive while no visible or palpable change in tissue at the site of injection and an increase of $2 \mathrm{~mm}$ or less $(\leq 2 \mathrm{~mm})$ in skin thickness with no oedema indicates a negative reaction. Swine reacted to either bovine or avian PPD were obtained using the formula:

$[(\operatorname{Bov} 48-\mathrm{Bov} 0)-(\operatorname{Av} 48-\mathrm{Av} 0)]>2 \mathrm{~mm}$ to bovine PPD and $[\mathrm{Av} 48-\mathrm{Av} 0)>2 \mathrm{~mm}$ to avian PPD. Bov0 and Av0 indicated skin thickness before injecting bovine and avian tuberculins, respectively. On the other hand, Bov48 and Av48 were the corresponding skin fold thickness $48 \mathrm{~h}$ post injection of bovine and avian tuberculins, respectively (OIE, 2009). 
Dairy cattle herded with swine were tuberculin skin tested following OIE (2009) recommendations with the aim to hypothesize interspecies transmission of bovine TB. Single intradermal comparative cervical tuberculin test (SICCTT) was used. The test results were read after $72 \mathrm{hrs}$. and interpreted using $\geq 4 \mathrm{~mm}$ cut-off values. In both dairy cattle and swine, a herd was considered as positive if it had at least one tuberculin reactor animal (OIE, 2009).

\section{Necropsy examination}

Whenever gross lesions suggestive of TB were detected in any of the tissues, the tissues were classified as having lesions. Hence, TB-like lesions were collected from 276 lymph nodes and tissues of swine slaughtered at AAAE. Necropsy and gross pathological examination were conducted following established protocols in FAO (1994).

\section{Histopathological examination}

Fat and other tissues were trimmed from TB-like lesions collected during necropsy examination. They were preserved in $10 \%$ neutral buffered formalin and transported to histopathological examination laboratory at the National Animal Health Diagnostics and Investigation Center (NAHDIC), Sebeta, Ethiopia. The tissue processing for histopathological examination was performed according to Santos et al. (2010) protocol. Briefly, the tissues were dehydrated in different grades of ethanol $(70 \%, 95 \%$ and $100 \%)$, cleared in xylene and refixed with formalin in an automatic tissue processing machine. Then, the tissues were embedded in paraffin using an embedding machine and cut into thin sections of $4-5 \mu \mathrm{m}$ using a microtome. Subsequently, the tissue sections were stained with haematoxylin and eosin and prepared for microscopic examination following the procedures described previously (Bancroft and Cook, 1994).

\section{Ethical consideration and clearance}

The ethical clearance for the study was provided by the Animal Research Ethics Review Committee of College of Veterinary Medicine and Agriculture, Addis Ababa University (CVMA-AAU) (Ethical Clearance Certificate Ref. No.: VM/ERC/007/03/09/2016). Swine suffering during skin test and antemortem inspection were ameliorated by safe handling. 


\section{Dataset Management and Statistical Analysis}

Data were entered and stored in separate MS-Excel 2007 spread sheet, thoroughly screened for errors, coded, imported and analyzed in Stata Version 12.0 for Windows. Descriptive statistics was used to determine the prevalence of swine TB. The associations of putative risk factors to swine TB were determined using chi-square $\left(\mathrm{x}^{2}\right)$ test of independence in univariate logistic regression. The strength of associations of the potential risk factors to swine TB was indicated by the odds ratio in multivariable logistic regression. The $95 \%$ CI other than a value of one and $P<0.05$ was set for statistical significance and effect of interactions. Swine herd was considered as a random effect and risk factors were considered as fixed effects. Variables in univariate logistic regression analysis were selected for multivariable logistic regression analysis when $P<0.05$. Variables were fitted separately to the final multivariable logistic regression model. A variable was considered to be a confounder and included in the model if its inclusion altered the OR of the estimated risk by $25 \%$ or more.

\section{Results}

\section{Prevalence and risk factors}

Dairy cattle herded with swine in one farm were tuberculin skin tested by using SICCTT. Of the total 28 dairy cattle tuberculin skin tested, 32\% (9/28; 95\% CI: 2-27) reacted to avian PPD, $86 \%$ (24/28; 95\% CI: $11-44)$ reacted to bovine PPD and 18\% (5/28; 95\% CI: 0.5-22) reacted to both avian and bovine PPDs at $\geq 4 \mathrm{~mm}$ cut-off value.

The SICTT was conducted on 329 heads of swine. The individual apparent prevalence of bTB in swine was $3 \%$ (10/329; 95\% CI: $2-6)$ at $>2 \mathrm{~mm}$ cut-off value. In the total 9 clusters tested, the herd prevalence was $11 \%(1 / 9 ; 95 \% \mathrm{CI}$ : 1-49). In addition, $2.7 \%$ (9/329; $95 \%$ CI: 6 -13) of swine reacted to avian PPD and $1.5 \%(5 / 329 ; 95 \% \mathrm{CI}: 3-8)$ reacted to both avian and bovine PPDs at $>2 \mathrm{~mm}$ cut-off value (Table 1 ). 
Table 1. Number and percent of swine positive to tuberculin skin test at $>2 \mathrm{~mm}$ value to different antigens by host related factors

\begin{tabular}{|c|c|c|c|c|c|c|c|}
\hline \multirow[t]{2}{*}{ Variables } & \multirow{2}{*}{$\begin{array}{l}\text { No. } \\
\text { tested }\end{array}$} & \multicolumn{6}{|c|}{ SICTT Results } \\
\hline & & $\begin{array}{l}\text { PPDA } \\
\text { positive }\end{array}$ & $\%$ & $\begin{array}{l}\text { PPDB } \\
\text { positive }\end{array}$ & $\%$ & $\begin{array}{l}\text { Mixed } \\
\text { positive }\end{array}$ & $\%$ \\
\hline Sex & 329 & 9 & 2.7 & 10 & 3 & 5 & 1.5 \\
\hline Male & 133 & 1 & 0.8 & 2 & 1.5 & 1 & 0.8 \\
\hline Female & 196 & 8 & 4.1 & 8 & 4.1 & 4 & 2 \\
\hline Age & 329 & 9 & 2.7 & 10 & 3 & 5 & 1.5 \\
\hline$<2$ years & 261 & 2 & 0.8 & 0 & 0 & 0 & 0 \\
\hline$\geq 2$ years & 68 & 7 & 10.3 & 10 & 14.7 & 5 & 7.4 \\
\hline BCS & 329 & 9 & 2.7 & 10 & 3 & 5 & 1.5 \\
\hline$\geq 5:$ Good & 105 & 0 & 0 & 0 & 0 & 0 & 0 \\
\hline [3-4]: Medium & 178 & 3 & 1.7 & 2 & 1.1 & 1 & 0.6 \\
\hline [1-2]: Poor & 46 & 6 & 13 & 8 & 17.4 & 4 & 8.7 \\
\hline $\begin{array}{l}\text { Physiological } \\
\text { state }\end{array}$ & 196 & 8 & 4.1 & 8 & 4.1 & 4 & 2 \\
\hline Open & 137 & 5 & 3.6 & 3 & 2.2 & 1 & 0.7 \\
\hline Pregnant & 59 & 3 & 5.1 & 5 & 8.5 & 3 & 5.1 \\
\hline Lactation status & 196 & 8 & 4.1 & 8 & 4.1 & 4 & 2 \\
\hline Non-lactating & 146 & 7 & 4.8 & 6 & 4.1 & 3 & 2.1 \\
\hline Lactating & 50 & 1 & 2 & 2 & 4 & 1 & 2 \\
\hline Parity & 196 & 8 & 4.1 & 8 & 4.1 & 4 & 2 \\
\hline No parity & 111 & 3 & 2.7 & 1 & 0.9 & 4 & 3.6 \\
\hline [1-3] Parity & 64 & 5 & 7.8 & 6 & 9.4 & 0 & 0 \\
\hline [4-6] Parity & 21 & 0 & 0 & 1 & 4.8 & 0 & 0 \\
\hline
\end{tabular}

No.: total number of swine tuberculin skin tested; BCS: body condition score; PPDA: avian purified protein derivative antigen; PPDB: bovine purified protein derivative antigen; Open: dry or non-pregnant

The gross pathological changes observed on the skin in some of test positive swine were nodular swelling characterized by firm erythematic nodules. The injection site constitutes a diffuse swelling, skin thickening, superficial necrosis and sloughing.

Univariate logistic regression analysis of host risk factors revealed body condition $(P=0.000)$ and parity $(P=0.026)$ were significantly associated with tuberculin skin test positivity. Moreover, physiological state of swine was associated 
to skin test positivity with marginal statistical significance $(P=0.058)$ (Table 2).

Table 2. The associations of different risk factors to swine skin test positivity post bovine PPD injection and interpreted at $>2 \mathrm{~mm}$ cut-off value

\begin{tabular}{|c|c|c|c|c|c|}
\hline \multirow[t]{2}{*}{ Variables } & \multirow{2}{*}{$\begin{array}{l}\text { No. } \\
\text { tested }\end{array}$} & \multicolumn{4}{|c|}{ SICTT Results } \\
\hline & & $\begin{array}{l}\text { PPDB } \\
\text { positive }\end{array}$ & $\%$ & $x^{2}$ & $P$-value \\
\hline Sex & 329 & 10 & 3 & 1.96 & 0.199 \\
\hline Male & 133 & 2 & 1.5 & & \\
\hline Female & 196 & 8 & 4.1 & & \\
\hline Age & 329 & 10 & 3 & 0.00 & - \\
\hline$<2$ years & 261 & 0 & 0 & & \\
\hline$\geq 2$ years & 68 & 10 & 14.7 & & \\
\hline BCS & 329 & 10 & 3 & 17.29 & $0.000^{*}$ \\
\hline$\geq 5$ : Good & 105 & 0 & 0 & - & \\
\hline [3-4]: Medium & 178 & 2 & 1.1 & & \\
\hline [1-2]: Poor & 46 & 8 & 17.4 & - & \\
\hline Physiological state & 196 & 8 & 4.1 & 3.74 & $0.058^{* *}$ \\
\hline Open & 137 & 3 & 2.2 & & \\
\hline Pregnant & 59 & 5 & 8.5 & & \\
\hline Lactation status & 196 & 8 & 4.1 & 0.00 & 0.973 \\
\hline Non-lactating & 146 & 6 & 4.1 & & \\
\hline Lactating & 50 & 2 & 4 & & \\
\hline Parity & 196 & 8 & 4.1 & 7.57 & $0.026^{*}$ \\
\hline No parity & 111 & 1 & 0.9 & & \\
\hline [1-3] Parity & 64 & 6 & 9.4 & & \\
\hline [4-6] Parity & 21 & 1 & 4.8 & & \\
\hline
\end{tabular}

BCS: body condition score; *: statistical significance; **: statistical marginal significance; Open: dry or nonpregnant

Multivariable logistic regression analysis revealed that body condition in swine has a protective exposure effect to tuberculin skin test positivity (adjusted OR $=0.06 ; 95 \%$ CI: 0.0-1.1) with statistical marginal significance $(P=0.055)($ Table $3)$. 
Table 3. Multivariable logistic regression analysis of tuberculin reactors' swine with the associated risk factors

\begin{tabular}{|c|c|c|c|c|c|}
\hline Variables & No. tested & $\begin{array}{l}\text { No. } \\
\text { positives }\end{array}$ & COR $(95 \% \mathrm{CI})$ & AOR (95\% CI) & $\begin{array}{l}P \text {-Value to } \\
\text { AOR }\end{array}$ \\
\hline \multicolumn{6}{|l|}{ Sex } \\
\hline Male & 133 & 2 & 1 & 1 & \\
\hline Female & 196 & 8 & $0.36(0.1-1.7)$ & $*$ & - \\
\hline \multicolumn{6}{|l|}{ Age (Years) } \\
\hline$<2$ & 261 & 0 & 1 & 1 & \\
\hline$\geq 2$ & 68 & 10 & - & $*$ & - \\
\hline \multicolumn{6}{|l|}{ BCS } \\
\hline$\geq 5:$ Good & 105 & 0 & - & - & \\
\hline [3-4]: Medium & 178 & 2 & 1 & 1 & \\
\hline [1-2]: Poor & 46 & 8 & $\begin{array}{c}0.05(0.01- \\
0.26)^{* *}\end{array}$ & $\begin{array}{c}0.06(0.00- \\
1.07)^{* *}\end{array}$ & $0.055^{* *}$ \\
\hline \multicolumn{6}{|l|}{ Physiol. state } \\
\hline Open & 137 & 3 & 1 & 1 & \\
\hline Pregnant & 59 & 5 & $\begin{array}{c}0.24(0.06- \\
1.05)\end{array}$ & $\begin{array}{c}1.17(0.06- \\
22.45)\end{array}$ & 0.917 \\
\hline \multicolumn{6}{|l|}{ Lactation } \\
\hline Non-lactating & 146 & 6 & 1 & 1 & \\
\hline Lactating & 50 & 2 & $1.03(0.2-5.27)$ & $\begin{array}{c}1.03(0.04- \\
25.63)\end{array}$ & 0.987 \\
\hline \multicolumn{6}{|l|}{ Parity } \\
\hline No parity & 111 & 1 & 1 & 1 & \\
\hline [1-3] parity & 64 & 6 & $\begin{array}{c}11.38(1.3- \\
96.79)\end{array}$ & $\begin{array}{c}3.80(0.08- \\
185.02)\end{array}$ & 0.501 \\
\hline [4-6] parity & 21 & 1 & $5.5(0.3-91.58)$ & $\begin{array}{c}1.54(0.05- \\
45.23)\end{array}$ & 0.803 \\
\hline
\end{tabular}

Ethiop. Vet. J., 2020, 24 (2), 16-34 


\section{Abattoir lesion prevalence}

The abattoir lesion prevalence in swine was $4.1 \%$ (26/640; 95\% CI: $2.8-6.0)$ (Table 4).

Table 4. Association of host related risk factors in relation to TB-like-lesions

\begin{tabular}{|c|c|c|c|c|c|c|c|}
\hline Variables & $\begin{array}{l}\text { No. } \\
\text { inspd }\end{array}$ & $\begin{array}{l}\text { No. } \\
\text { positive }\end{array}$ & $\begin{array}{l}\text { Prevalence } \\
(\%)\end{array}$ & $\mathrm{X}^{2}$ & OR & $\begin{array}{l}95 \% \text { CI } \\
\text { for OR }\end{array}$ & $P$-value \\
\hline Sex & 640 & 26 & 4.1 & 0.85 & 1.46 & $0.64-3.33$ & 0.365 \\
\hline Female & 277 & 9 & 3.2 & & & & \\
\hline Male & 363 & 17 & 4.7 & & & & \\
\hline Age & 640 & 26 & 4.1 & 2.21 & 1.81 & $0.83-4.00$ & 0.137 \\
\hline$<2$ years & 386 & 12 & 3.1 & & & & \\
\hline$\geq 2$ years & 254 & 4 & 1.6 & & & & \\
\hline BCS & 640 & 26 & 4.1 & 0.82 & 1.16 & $0.45-3.00$ & 0.753 \\
\hline Poor & 206 & 7 & 3.4 & & & & \\
\hline Medium & 305 & 12 & 3.9 & & & & \\
\hline Good & 129 & 7 & 5.4 & & & & \\
\hline Origin & 640 & 26 & 4.1 & 0.51 & 1.29 & $0.55-3.03$ & 0.558 \\
\hline $\mathrm{AA}$ & 262 & 9 & 3.4 & & & & \\
\hline Bishoftu & 319 & 14 & 4.4 & & & & \\
\hline Others & 59 & 3 & 5.1 & & & & \\
\hline
\end{tabular}

No. inspd: total number of swine inspected; OR: Odds Ratio; AA: Addis Ababa; Others: refer to names of regional towns like Bahr Dar, Debre Berhan, Dessie and Gondar.

\section{Gross pathology and histopathology}

Gross pathological characterization of TB-like lesions revealed caseous, enlarged and cheesy in submandibular lymph nodes. Lesions in the retropharyngeal lymph nodes were characterized as purulent, early caseation and caseous. The mesenteric lymph nodes were enlarged. Caseous lesions were observed in the spleen. Focal calcification was observed in the liver. White spots, focal calcification and caseous lesions were seen in the lungs. Gross TB-like lesions in the present study were repeatedly encountered in retropharyngeal (27\%: 7/26), submandibular (12\%: $3 / 26)$ and mesenteric (15\%: 4/26) lymph nodes as well as $4 \%(1 / 26)$ in each of the lungs, spleen and liver. 
Histopathological analysis of TB-like lesions revealed granulomas with central necrosis and calcification. The histological arrangement from the center to outer was made up of lymphocytes, macrophages and epithelioid cells distributed under connective tissue layers. Moreover, the central area is made of necrotic cellular debris, calcium deposits and connective tissue capsule walled off the granulomas from the surrounding tissue. The presence of concomitant pyogranulomatous and granulomatous lesions in different organs were also observed. Some granulomas were characterized by necrotic foci, intense calcification and fibrosis with absence of epithelioid cells. Multiple small granulomas in the lymph node with less dense lymphocyte at periphery and epithelioid cells surrounding the deep outer lymphatic layer of the granulomas were observed.

\section{Discussion}

The current study of swine TB by making use of SICTT is the first of its kind executed in Ethiopia. Tuberculin skin test and necropsy were employed to investigate the epidemiology of swine TB in central Ethiopia. Skin test (3\%) and necropsy (4.1\%) studies have confirmed the occurrence of swine TB at low prevalence in central Ethiopia. The lower relative prevalence of TB in swine is due to the tendency of the disease to remain localized in this species and the early age of slaughter (Radostits et al., 2007).

The greater of the reactions to either avian PPD or bovine PPD indicates the organism responsible for sensitization. There exists no clear evidence on the immunological relationship between these two but studies have shown that co-infection with MAC compromises bTB skin test results by negatively influencing the sensitivity of the tuberculin test. Some decrease in skin sensitivity after parturition occurs in sows infected with $M$. bovis but may not occur when the infection is associated with $M$. avium (Radostits et al., 2007). Cattle sensitized by MAC might conceal $M$. bovis for a period of time. However, it is not clear to what extent this disease could jeopardize the detection of bTB with skin test thus requiring further research (Mekonnen et al., 2019).

SICCTT in this study revealed $86 \%$ of dairy cattle herded with swine reacted to bovine PPD. Cattle served as sources of infection to swine in bTB endemic farms (Arega et al., 2013). When the disease is common among dairy cattle in an area, $10-20 \%$ of the local swine are likely to be infected due to interspecies transmission from bovine to swine. Uninfected swine can easily get bacilli from their contaminated bedding, feed and drinking water (Radostits et al., 2007). Inhalation of infected aerosols or feeding on contaminated feed or water might

Ethiop. Vet. J., 2020, 24 (2), 16-34 
be hypothesized to be sources of mycobacterial infection to swine in the current study. The predominant reaction of swine and bovine to bovine PPD in the current study has indicated its zoonotic risk to human beings in the commonly experienced shelter sharing of swine with human beings and herding together different species of livestock in Ethiopia.

The tuberculin skin test was evaluated in Arizona as an epidemiological tool for measuring prevalence of TB infection in swine herd and $63.3 \%$ of swine revealed positive responses. At slaughter, $61.5 \%$ were shown to have TB-like lesions in one or more lymph nodes of the digestive tract. A good correlation (97.1\%) exists between skin test reactors and swine with lesions (Matlova et al., 2004).

Female swine in this study were more reactive to bovine PPD than males due to their longer duration in the farms. Adult female breeding animals had longer and repeated chance of exposure to mycobacterial infection due to factors such as lactation, pregnancy and parturition which all are physiological stressors that suppress the immune responsiveness (Ameni et al., 2007; Elias et al., 2008; Mamo et al., 2013; Terefe, 2014; Bekele et al., 2016) and might cause infection via endogenous reactivation of bacili. The immunological hyporeactivity that occurs in association with pregnancy and parturition generally makes pregnant sows susceptible to the disease (Radostits et al., 2007).

Swine with poor body condition were more affected in this study and field observation revealed poor feeding regimen. Stress caused by poor feeding in animals could subject to severe diseases like TB (Ameni et al., 2006). Higher prevalence of bTB was reported in animals with poor body condition which conforms well to the established fact that animals' resistance to TB is reduced by a shortage of feed and/or unbalanced diet attributable to a deficiency of proteins, minerals and vitamins in the diet (Elias et al., 2008). In addition, poor conditioned animals were susceptible to bTB infection due to weak immunological responses (Nuru et al., 2015).

Necropsy revealed low prevalence of TB-like lesions in slaughtered swine in the current study. Necropsy has low sensitivity of lesion detection (Shitaye et $a l ., 2007)$ due to lack of visible lesions in tuberculin reactors in the early stage of infection (Tsegaye et al., 2010). However, some dairy cattle without visible lesions were culture positive which may be due to prior spread of the bacterium in the tissues during an early stage of infection but yet to result in lesion (Berg et al., 2009). The lesion prevalence in the present study is higher than $0.009 \%$ 
(Shitaye et al., 2006), 0.02-1.83\% (Shitaye et al., 2007) and 1.48\% (Bogale et al., 2004) but slightly lower than 5.16\% (Ameni and Wudie, 2003) and 5.8\% (Arega et al., 2013). Arega et al. (2013) experienced 67\% (563/841) of the swine brought for slaughter were less than one year of age. Experience indicated that swine are slaughtered at their early age for digestible pork.

Significantly higher number of swine $>1$ year of age were found to be lesioned than those of $\leq 1$ year (Arega et al., 2013) which supported the frequent observation of gross TB-like lesions in swine of $\geq 2$ years of age in this study. Gross TB-like lesions in the present study were repeatedly encountered in lymph nodes of the gastrointestinal tract. The percentage of gross TB-like lesions was the highest (29\%) in submandibular lymph node and the lowest (6\%) in mediastinal lymph node (Arega et al., 2013) which is congruent to this finding. Majority of TB-like lesions were detected in swine where localization as nonprogressive abscesses occurs in the lymph nodes of the head and neck (Radostits et al., 2007; Ameni et al., 2013).

The study in the Czech Republic detected TB-like lesions in 3.6\% of the slaughtered swine (Matlova et al., 2004). Among the predominant localization of TBlike lesions in mesenteric and cervical lymph nodes in slaughtered swine, it could be suspected that animals were primarily infected by the ingestion of mycobacteria (Songer et al., 1980; Matlova et al., 2004). Study on environmental source of mycobacteriosis in swine which were exposed to dirt pens and then slaughtered in California revealed an abattoir TB-like lesion prevalence of 9.4\% (Gardener and Hird, 1989).

Haematoxylin-eosin (H-E) stained TB-like lesions in histological analysis in this study revealed the presence of lymphocytes, epithelioid cells, necrotic cellular debris, fibrosis, calcification and necrosis. Parallel to this, Ameni et al. (2000) indicated the presence of cellular infiltration, macrophages, giant cells, necrosis or calcification in H-E stained tissues in dairy cattle. Moreover, soft foci of caseous necrosis were usually present upon gross and microscopic examination (Songer et al., 1980) which is in line with the present finding.

\section{Conclusion}

Tuberculosis in swine in the study area occurred in low prevalence. 


\section{Limitation of the study}

Swine farm owners were not voluntary for their swine to be PPD tested and hence small sample size was one of the limitations. In addition, the mycobacterial species in swine were not identified and characterized due to time limitation.

\section{Conflict of interest}

The authors declared there is no conflict of interest exists.

\section{Acknowledgements}

The authors would like to acknowledge the TB laboratory of Aklilu Lemma Institute of Pathobiology (ALIPB), participated professionals from CVMA-AAU, animal health and production staffs of Oromia, owners of swine farms and field staffs for their time. Ali Gebeyehu and Dr. Estifanos Lemma are acknowledged for development of the GIS map to indicate the study sites.

\section{References}

Agdestein, A., Johansen, T.B., Polacek, V., Lium, B., Holstad, G., Vidanovic, D., et al., 2011. Investigation of an outbreak of mycobacteriosis in pigs. BMC Vet. Res., 7, 63.

Ameni, G., Miorner, H., Roger, F. and Tibbo, M., 2000. Comparison between Comparative Tuberculin and Gamma-Interferon Tests for the Diagnosis of Bovine Tuberculosis in Ethiopia. Trop. Anim. Hlth. Prod., 32, 267-276.

Ameni, G., Belay, M. and Medhin, G., 2003. A Preliminary study on bovine tuberculosis in stallholder farms and its zoonotic implication to owners in Fitche town, central Ethiopia.

Sudan J. Vet. Res., 18, 37-46.

Ameni, G. and Wudie, A., 2003. Preliminary study on bovine tuberculosis in Nazareth municipality abattoir of central Ethiopia. Bulletin Anim. Hlth. Prod. Africa, 51, 125-132.

Ameni, G., Aseffa, A., Engers, H., Young, D., Hewinson, G. and Vordermeier. M., 2006. Cattle Husbandry in Ethiopia Is a Predominant Factor Affecting the Pathology of Bovine Tuberculosis and Gamma Interferon Responses to Mycobacterial Antigens.

Clin. Vaccine Immunol., 13(9), 1030-1036. 
Ameni, G., Aseffa, A., Engers, H., Young, D., Gordon, S., Hewinson, G., et al., 2007. High Prevalence and Increased Severity of Pathology of Bovine Tuberculosis in Holsteins Compared to Zebu Breeds under Field Cattle Husbandry in Central Ethiopia. Clin Vaccine Immunol., 14(10), 1356-1361.

Ameni, G., Tadesse, K., Hailu, E., Deresse, Y., Medhin, G., Aseffa, A. et al., 2013. Transmission of Mycobacterium tuberculosis between Farmers and Cattle in Central Ethiopia. $\quad P L o S O N E, 8$, e76891.

APHA, 2019. Animal and Plant Health Agency (APHA) of the Gov. UK as updated as of 9:21 on 07/08/2019, APHA, London, UK. Available at http://apha.defra.gov.uk/External_OV_Instructions/TB_Pig_Instructions/Skin_Test/Skin_Test ay_Two.html.

ArcGIS Software, 2019. Basic tool for mapping and spatial data. Latest version 2019.

Arega, S.M., Conraths, F. J. and Ameni, G., 2013. Prevalence of tuberculosis in pigs slaughtered at two abattoirs in Ethiopia and molecular characterization of $M y$ cobacterium tuberculosis isolated from tuberculous-like lesion in pigs. BMC Vet. Res., 9, 1-9.

Bancroft, J. and Cook, H., 1994. Manual of histological techniques and their diagnostic application. Churchill Livingston \& Longman, London, Pp 244-247.

Barandiaran, S., Vivot, M.M., Moras, E.V., Cataldi, A.A. and Zumarraga, M. J., 2011. Mycobacterium bovis in Swine: Spoligotyping of Isolates from Argentina. Vet. Med. Int., 6 pages.

Bekele, M., Mamo, G., Mulat, S., Ameni, G., Beyene, G. and Tekeba, E., 2016. Epidemiology of Bovine Tuberculosis and Its Public Health Significance in Debre Zeit Intensive Dairy Farms, Ethiopia. Biomed Nursing, 2(2), 8-18.

Berg, S., Firdessa, R., Habtamu, M., Gadisa, E., Mengistu, A., et al., 2009. The Burden of Mycobacterial Disease in Ethiopian Cattle: Implications for Public Health. PLoS ONE, 4, e5068.

Bogale, A., Woldesenbet, Z., Yimer, E. and Lemma, E., 2004. Evaluation of abattoir inspection for the diagnosis of Mycobacterium bovis infection in cattle at Addis Ababa abattoir. Trop. Anim. Hlth. Prod., 36, 537-546.

CFIA, 2019. Canadian Food Inspection Agency (CFIA) Tuberculosis Testing. Available at

https://www.inspection.gc.ca/animals/terrestrial-animals/diseases/accredited-veterinarian-s-manual/chapter-3/eng/1345233051622/1345233162747?chap=1.

CFSPH, 2011. Body Condition Score-Swine. USDA Animal and Plant Health Inspection Service (APHIS), National Veterinary Accreditation Program, the Center for Food Security and Public Health (CFSPH), Iowa State University, USA, P1. 
Cosive, O., Meslin, F. X., Daborn, C. J. and Grange, J. M., 1995. Epidemiology of $M y$ cobacterium bovis infection in animals and humans with particular reference to Africa. Rev. Sci. Tech. Off Int. Epiz., 14(3), 733-746.

Cosivi, O., Grange, J. M., Daborn, C. J., Raviglione, M. C., Fujikura, T., Cousins, D., et al., 1998. Synopses on Zoonotic Tuberculosis due to Mycobacterium bovis in Developing Countries. EID., 4(1), 59-70.

Elias, K., Hussein, D., Bogale, A., Tsegaye W. and Gebeyehu, M., 2008. Status of bovine tuberculosis in Addis Ababa dairy farms. Rev. Sci. Tech. Off Int. Epiz., 27(3), 915923.

FAO, 1994. Specific diseases of cattle-tuberculosis. In: Manual on meat inspection for developing countries. FAO Animal Production and Health Paper 119, Rome, Italy. http://www.fao.org/docrep/003/t0756e/T0756E03.htm

Gardner, I.A. and Hird, D.W., 1989. Environmental Source of Mycobacteriosis in a California Swine Herd. Can. J. Vet. Res., 53(1), 33-37.

Mamo, G., Abebe, F., Worku, Y., Hussein, N., Legesse, M., Tilahun, G., et al., 2013. Bovine tuberculosis and its associated risk factors in pastoral and agro-pastoral cattle herds of Afar Region, Northeast Ethiopia. J. Vet. Med. Anim. Hlth., 5(6), 171-179.

Matlova, L., Dvorska, L., Palecek, K., Maurenc, L., Bartos, M. and Pavlik, I., 2004. Impact of sawdust and wood shavings in bedding on pig tuberculous lesion in lymph nodes, and IS1245 RFLP analysis of Mycobacterium avium subsp. hominissuis of serotypes 6 and 8 isolated from pigs and environment. Vet. Microbiol., 102(3-4), 227-236.

Mekonnen, G.A., Conlanb, A.J. K., Berg, S., Teshome, B.A., Alemu, A., Guta, S., et $a l ., 2019$. Prevalence of bovine tuberculosis and its associated risk factors in the emerging dairy belts of regional cities in Ethiopia. Prev. Vet. Med., 168, 81-89.

Nuru, A., Mamo, G., Teshome, L., Zewude, A., Medhin, G., Pieper, R. and Ameni, G., 2015. Bovine tuberculosis and its risk factors among dairy cattle herds in and around Bahr Dar City, Northwest Ethiopia. Ethiop. Vet. J., 19(2), 27-40.

OIE, 2009. Bovine tuberculosis. OIE Manual of Diagnostic Tests and Vaccines for Terrestrial Animals. Office International des Epizooties (OIE), Paris, France, Pp1-12.

OIE, 2019. Bovine tuberculosis. Office International des Epizooties (OIE), Paris, France.

PRiONiCS, 2015. PRiONiCS Lelystad B. V., Tuberculin PPD Kit solution for injection. Platinastraat 33, 8211 AR Lelystad, The Netherlands.

Radostits, O. M., Gay, C. C., Hinchcliff, K. W. and Constable, P. D., 2007. Tuberculosis associated with Mycobacterium bovis. In: Veterinary Medicine, a textbook of the 
diseases of Cattle, Horses, Sheep, Pigs and Goats (10 $10^{\text {th }}$ Ed). W.B. Saunders, Edinburgh, London, Pp 1007-1014.

Santos, N., Geraldes, M., Afonso, A., Almeida, V. and Correia-Neves, M., 2010. Diagnosis of Tuberculosis in the Wild Boar (Sus scrofa): A Comparison of Methods Applicable to Hunter-Harvested Animals. PLoS ONE, 5, e12663.

Shitaye, J.E., Getahun, B., Alemayehu, T., Skoric, M., Treml, F., Fictum, P., et al., 2006. A prevalence study of bovine tuberculosis by using abattoir meat inspection and tuberculin skin testing data, histopathological and IS6110 PCR examination of tissues with tuberculous lesion in cattle in Ethiopia. Veterinarni Medicina, 51, $512-522$.

Shitaye, J.E., Tsegaye, W. and Pavlik, I., 2007. Bovine tuberculosis infection in animal and human populations in Ethiopia: a review. Veterinarni Medicina, 52, 317-332.

Sibhat, B., Asmare, K., Demissie, K., Ayelet, G., Mamo, G. and Ameni, G., 2017. Bovine tuberculosis in Ethiopia: A systematic review and meta-analysis. Prev. Vet. Med., 147, 149-157.

Songer, J.G., Bicknell, E.J. and Thoen, C.O., 1980. Epidemiological Investigation of Swine Tuberculosis in Arizona. Can. J. comp. Med., 44, 115-120.

Stata, 2012. Stata Corporation. Stata statistical software, Release 12.0. 4905 Lakeway Drive, College Station, Texas, USA.

Thrusfield, M., 2007. Surveys. In: Veterinary Epidemiology, $3^{\text {rd }}$ ed., Blackwell Science Ltd, Oxford, UK, Pp 233-245.

Terefe, D., 2014. Gross pathological lesions of bovine tuberculosis and efficiency of meat inspection procedure to detect infected cattle in Adama municipal abattoir. J. Vet. Med. Anim. Hlth., 6, 48-53.

Tsegaye, W., Assefa, A., Mache, A., Mengistu, Y., Berg, S. and Ameni, G., 2010. Conventional and Molecular Epidemiology of Bovine Tuberculosis in Dairy Farms in Addis Ababa City, the Capital of Ethiopia. Int. J. App. Res. Vet. Med., 8, 143-151.

USDA, 2018. Feral Swine Aging Photo Guide. United States Department of Agriculture (USDA) and Animal and Plant Health Inspection Service (APHIS), Wildlife Services, Pp 1-4. 